Book Review

\title{
Romance Languages and Linguistic Theory 2005. Current Issues in Linguistic Theory 291
}

\author{
ACRISIO PIRES \\ University of Michigan, Ann Arbor \\ Linguistics Department \\ pires@umich.edu
}

Romance Languages and Linguistic Theory 2005. Edited by Sergio Baauw, Frank Drijkoningen \& Manuela Pinto (2007). Current Issues in Linguistic Theory 291. Amsterdam: John Benjamins.

This book constitutes a very useful collection of papers primarily on the acquisition of syntax and, to a lesser extent, on theoretical syntax and its interfaces with semantics, phonology and morphology. As it is often the case for book collections on Romance linguistics, the papers explore primarily Spanish, French and Italian (as a notable exception, three of the ten acquisition papers investigate Portuguese).

In Alcazar and Saltarelli's The quirky case of participial clauses they used data from Italian and Spanish to propose that adverbial participial clauses exhibit quirky case properties, and the internal argument of a transitive verb may bear accusative or nominative morphological case in Romance. Unlike gerundival clauses, these clauses are taken to lack $\mathrm{T}$ and $\mathrm{v}^{*}$ (or $v$ ), among other heads, undermining a standard case licensing approach. The authors propose that absolutes are VPs that value the case of their internal argument, avoiding stipulative alternatives which fail to capture the relevant paradigm in Romance, such as a morphological default/inherent case approach. 
Di Sciullo (On Affixal Scope and Affix-Root Ordering in Italian) considers why different sorts of affixes occupy different canonical positions in morphological expressions, and argues that the semantic scope between affixes and the precedence relations between affixes and roots at PF follow from the position of affixes in their minimal trees according to Asymmetry Theory (Di Sciullo 2005), given a linearization operation that applies to the units of morphological domains. She provides evidence that affixal scope, legible at LF, is derived by morphological operations applying under asymmetric Agree.

On The Ambiguity of $\mathrm{N}$-Words in French, by Kuno presents evidence that n-words in French are ambiguous between negative quantifiers and bipolar items, polar sensitive items that must occur in the contexts that license both negative and positive polarity items. The author attempts to derive their semantic ambiguity from a single underlying lexical entry. The ambiguity approach partially follows from Herburger's (2001) analysis of n-words in Spanish, in which n-words are argued to be lexically ambiguous between negative quantifiers and negative polarity items. For Kuno the difference between n-words in French and n-words in Spanish falls out from differences in the structural position of sentential negation.

Ordonez addresses the Cartography of Postverbal Subjects in Spanish and Catalan. In many recent analyses of V S O structures in Romance, subjects have been assumed to be in situ in Spec VP. Ordonez argues instead that they move to a Spec position above VP (SubjP), below the final landing site of verbs in TP. $\mathrm{He}$ presents supporting evidence from Catalan and Spanish, which differ minimally in patterns of subject inversion with respect to quantifiers, adverbs and restructuring contexts. Unfortunately, such a proposal introduces a new syntactic projection instead of appealing directly to various analyses in which intermediate projections with similar properties have been proposed between TP and VP, which raises question regarding the parsimonious nature of the proposal to account for micro-parametric differences.

Two papers deal with the interface between syntax and phonology. In Metrical Structure, Tonal Association and Focus in French, Delais-Roussarie $\&$ Rialland argue that focus is a pivot in tune-text association, which plays a central role for the anchoring of intonational tones. Their paper also presents the main characteristics of the French prosodic system and provides an overview of French metrical structure. Jouitteau (Listen to the Sound of Salience: Multichannel Syntax of $Q$ Particles) argues that the linguistic message that realizes syntax is multichannel. By investigating $Q$ particles in French, Atlantic French and British English, she argues that the realization of syntactic structure consists of segmental oral morphemes, non-segmental oral morphemes (intonation) and, more controversially in the case of oral languages, non-oral morphemes (segmental or not) corresponding to hand movements, upper body gestures and face movements. A conceptual support 
for this argument is that native speakers of oral languages have all three types of morphemes in their sensorimotor system.

Two papers address the syntax-semantics interface more directly. Javier Gutierrez-Rexach (When Scope Meets Modality: The Scope of Indefinites in Subjunctive Environments) revisits the claim that subjunctive mood affects the referential possibilities of Spanish indefinite DPs. He argues that purely-semantic accounts cannot explain why relative clauses seem to behave as stronger blocking environments than other structurally-similar domains. $\mathrm{He}$ explores how restrictions on the derivation of relative clauses prevent certain indexing possibilities, as part of a syntax/semantics interface approach. In Scope Economy in Positive Polarity: Extreme Degree Quantification, Gonzalez Rodriguez focuses on degree expressions in Spanish, such as extremadamente 'extremely', arguing that they cannot occur in negative sentences, thus patterning with Positive Polarity Items (PPIs). Contrary to the standard syntactic view on polarity items, she argues that these new PPIs remain in the structural position where they are merged, without checking any positive feature by movement or Agree with higher functional projections. She takes these PPIs to be incompatible with negation because they denote extreme degree quantification, affirming emphatically the degree to which a property is held.

Turning to acquisition, three papers investigate properties of null elements in L1 acquisition, two of them focusing on European Portuguese. Costa \& Lobo (Clitic Omission, Null Objects or Both in the Acquisition of European Portuguese?) present results of an experimental acquisition study on the availability of null objects and variability of clitic positions. Previous studies (e.g. Wexler et al. 2003) have argued that early clitic omission is expected in languages with past participle agreement. Since Portuguese doesn't show past participle agreement, Portuguese children are expected to produce clitics early on. However, the author's results indicate that Portuguese children do omit clitics, apparently contradicting previous studies. Since clitic omission lasts until later than in other languages, they hypothesize that the explanation lies in complexity factors involving the clitic placement and the existence of null objects.

Santos (A Poverty of the Stimulus Argument for the Innateness of the Identification Conditions On VP Ellipsis) argues that the co-existence in European Portuguese of Null Complement Anaphora and of VP ellipsis licensed by main verbs yields learnability problems and provides a poverty-of-the stimulus argument for the innateness of the identification conditions on VP ellipsis. VP ellipsis is predicted to be acquired as early as V-to-I, if the identification constraint operating on ellipsis derives from innate principles that interact with an I-language dependence between both phenomena. Santos shows spontaneous production evidence that children produce VP ellipsis as early as 1;6 in simple contexts such as answers to yes-no questions, and takes this as evidence of early V-to-I. 
Panneman and Weerman investigate Mismatches between Phonology and Syntax in French DP Acquisition, considering determiner omission in child language. Previous studies account for determiner omission by assuming that the D-layer is not available at the onset of acquisition. However, these models are forced to postulate structures that conflict with the referential properties of bare nouns in child language. The authors argue that the D-layer is available in very early stages, although the DP-structure is acquired item-by-item rather than as the result of rule-based mechanisms, and the correspondence between phonological items and their syntactic representations is not target-like at first. Although the approach is proposed to account for continuity between child and adult grammar, it is not entirely clear how this is ensured by the properties of the proposed model. Gualmini investigates Mechanisms of Scope Resolution in Child Italian, testing children's interpretation of the Italian indefinite qualche and of negation with universal quantifiers. He shows experimental evidence that Italian speaking children's interpretation of qualche in sentences with negation is not limited to surface scope interpretations.

Belletti (Answering Strategies) considers speakers' grammaticality judgments in combination with acquisition data, specifically from L2 acquisition, to help clarify theoretical issues concerning grammatical choices (such as SV/VS orders and (reduced) clefts) made to answer questions on the identification of the subject, especially in Italian and French. Belletti analyzes different answering strategies as involving either a VP-peripheral internal focus position or focalization in situ. She argues different answering strategies are in place early on in first language monolingual acquisition, and are all in principle available in different languages, provided that no formal condition is violated in the interaction with other properties, such as the null-subject vs. non null-subject nature of the language.

Five other papers focus on bilingual or L2 acquisition. In Cross-Linguistic Influence in Bilingual Children: The Case of Dislocation, Notley, van der Linden and Hulk revisit a proposal by Hulk \& Mülller's (2000) of cross-linguistic influence in early child bilingualism, which Serratrice et al. (2004) attempted to extend to cases of influence after instantiation of the C-system (at a later stage of development). The authors investigate whether this extension can successfully account for the use of dislocation, a topic marking device, in French-English and French-Dutch bilingual children. They argue their results support the extension of the model, by identifying the predicted cross-linguistic influences in the bilingual data. However, certain aspects of their results cannot be sufficiently accounted for under the extended formulation, leading them to consider other factors which may interact with those proposed in Hulk \& Müller's model, such as input frequency, transparency of syntactic-pragmatic mapping, complexity of syntactic structures and Chomskyian economy.

Cabrera \& Zubizarreta (Transfer in Periphrastic Causatives in L2 English and L2 Spanish) report the results of a bidirectional study on the L2 
acquisition of English and Spanish periphrastic causatives by adult learners. They argue that different L1 grammatical properties are transferred at different levels of L2 proficiency, supporting a view of transfer as a developmentally constrained process. At earlier stages, L2 learners focus on L1 word order properties whereas at an advanced proficiency stage, L1 distinctions between causation types encoded by certain periphrastic causatives are taken to be more relevant.

In The Acquisition of Aspect in L2 Portuguese \& Spanish: Exploring Native/Non-Native Performance Differences, Goodin-Mayeda and Rothman investigate the possibility of L2 native-like ultimate attainment. They tested highly proficient English L2 learners of Portuguese and Spanish, and showed that there is no statistically significant distinction between the L2 speakers and monolinguals regarding semantic entailments associated with the Preterit/ Imperfect aspect contrast. However, they show a related pattern of target-deviant L2 performance, which they take to be affected by explicit positive evidence (pedagogical rules) despite otherwise demonstrable native-like competence. They show target-deviant performance in three specific contexts, all of which they assumed can be linked to traditional instruction that simplifies the aspectual contrast: with particular stative verbs taken to be uncommon in the Preterit (e.g. ser, estar), when preceded by certain adverbial phrases (e.g., siempre) and with a class of semantic shifting verbs (e.g., sabía vs. supe).

In Pragmatic Solutions for Syntactic Problems: Understanding Some L2 Syntactic Errors in Terms of Discourse-Pragmatic Deficits, Rothman considers target-deviant aspects of L2 grammars within a UG-continuity framework. He examines the resetting of the Null-Subject Parameter (NSP) for English learners of L2 Spanish, arguing that insensitivity to discourse pragmatic constraints on the distribution of overt/null subjects accounts for what appear to be errors resulting from syntactic deficits. He argues that despite target-deviant performance, the majority of his subjects must have native-like syntactic competence given their knowledge of the Overt Pronoun Constraint (Montalbetti 1984).

Finally, Kras (Instability and Age Effects at the Lexicon-Syntax Interface) addresses the instability of the lexicon-syntax interface in bilingual L1 and L2 acquisition, as well as age effects of first exposure to the L2 on ultimate attainment of this interface. She investigates auxiliary selection with intransitive verbs in Italian, whose orderly gradience is captured by the Auxiliary Selection Hierarchy. She applied an acceptability-judgment task to child and adult Croatian advanced/near-native L2 speakers, Croatian-Italian simultaneous bilinguals and Italian L1 speakers. Both bilingual L1 and L2 speakers were sensitive to the gradience in auxiliary selection with intransitive verbs, but had less determinate intuitions than monolingual L1 speakers, providing evidence for the instability of the lexicon-syntax interface in non-monolingual development. In addition, adult L2 speakers proved to be less sensitive to the gradience than child L2 speakers, providing evidence of the 
interaction between age of first exposure to the L2 and acquisition of the lexicon-syntax interface.

\section{References}

Di Sciullo, A. M. (2005) Asymmetry in morphology. Cambridge, MA: MIT Press.

Herburger, E. (2001) Negative concord puzzle: Revisited. Natural Language Semantics 9, 289-333.

Hulk, A. \& N. Müller (2000) Bilingual first language acquisition at the interface between syntax and pragmatics. Bilingualism: Language and Cognition 3(3), 227-244 .

Serratrice, L., A. Sorace \& S. Paoli (2004) Subjects and objects in Italian-English bilingual and monolingual acquisition. Bilingualism: Language and Cognition $\mathbf{7}$, 183-206.

Montalbetti, M. (1984) Binding: On the interpretation of pronouns. Ph.D. dissertation, MIT.

Wexler, K., A. Gavarró \& V. Torrens (2003) Feature checking and object clitic omission in child Catalan and Spanish. In Romance Languages and Linguistic Theory 2003 (R. Bok-Bennema, B. Hollebrandse, B. Kampers-Manhe \& P. Sleeman, editors), pp. 253-269. Amsterdam: John Benjamins. 